\title{
Radiation Protection of a Patient Undergoing an Orthopedic Procedure by Using a Mobile C-Arm X-Ray System
}

\author{
Natasha Ivanova \\ Department Physics and Biophysics, Medical University “Prof. Dr. Paraskev Stoyanov", Varna, Bulgaria \\ Email: natasha_i@abv.bg
}

How to cite this paper: Ivanova, N. (2020) Radiation Protection of a Patient Undergoing an Orthopedic Procedure by Using a Mobile C-Arm X-Ray System. International Journal of Medical Physics, Clinical Engineering and Radiation Oncology, 9, 141-156.

https://doi.org/10.4236/ijmpcero.2020.93013

Received: July 25, 2020

Accepted: August 24, 2020

Published: August 27, 2020

Copyright $\odot 2020$ by author(s) and Scientific Research Publishing Inc. This work is licensed under the Creative Commons Attribution International License (CC BY 4.0).

http://creativecommons.org/licenses/by/4.0/

\begin{abstract}
Modern medicine is unthinkable without X-rays. Accurate diagnosis, leading to effective treatment, is largely based on precise X-ray examinations. The creation of new, modern equipment and various medical procedures that meet the increased requirements are a priority in our time. X-ray examinations are of particular importance for the orthopedic and traumatological clinics, where they provide information about presence of a fracture in the patient's body, about the concrete operation performed or about the effect of a suitable treatment. Along with their benefits X-rays have also a harmful effect. This requires special care to protect from this radiation. In this direction, research is constantly being done to improve the quality of radiation protection. Park MR, Lee KM and co-authors, compare the dose load obtained using $\mathrm{C}$-arm and $\mathrm{O}$-arm X-ray systems (which have the capability of combined 2D fluoroscopy and 3D computed tomography imaging). In their study, an orthopedic surgical procedure using $\mathrm{C}$-arm and $\mathrm{O}$-arm systems in $2 \mathrm{D}$ fluoroscopy modes was simulated. The radiation doses to susceptible organs of the operators were investigated. He results obtained show that the O-arm system delivered higher doses to the sensitive organs of the operator in all configurations [1]. The article of Stephen Balte briefly reviews the available technologies for measuring or estimation of patient skin dose in the interventional fluoroscopic environment, created by various $\mathrm{X}$-ray equipment including C-arm systems. Given that many patients require multiple procedures, this documentation also aids in the planning of follow up visits [2]. Chong Hing Wong, Yoshihisa Kotani and co-authors evaluate the radiation exposures (RE) to the patient and surgeon during minimally invasive lumbar spine surgery with instrumentation using $\mathrm{C}$-arm image intensifier or $\mathrm{O}$-arm intraoperative CT. The results they get are in favor of the O-arm system [3]. The article "Virtual fluoroscopy for intraoperative C-arm positioning and
\end{abstract}


radiation dose reduction" discusses positioning of an intraoperative C-arm system to achieve clear visualization of a particular anatomical feature by a system for virtual fluoroscopy (called FluoroSim) that could dramatically reduce time and received dose during the procedures. FluoroSim was found to reduce the radiation exposure required for $\mathrm{C}$-arm positioning without reducing positioning time or accuracy, providing a potentially valuable tool to assist surgeons [4]. In our study, we performed practical measurements to show how the patient can be treated by applying most effective radiation protection when using a mobile C-arm X-ray system. For the study, we used exposure upon a phantom placed on the patient's table. For an X-ray shielding, we used a protective apron with a lead equivalent of $1 \mathrm{~mm}$, placed in two layers on the phantom. In each subsequent series of exposures, the protective apron was placed on the phantom, in a different position relative to the X-ray beam. The general conclusion of our study is that in order to obtain maximum protection from scattered radiation when using C-arm X-ray systems, the patient must be protected by a shielding with a suitable lead equivalent for the procedure performed which must be placed between patient's body and $\mathrm{X}$-ray tube, perpendicular to the X-ray beam pointed toward the region of interest.

\section{Keywords}

C-Arm X-Ray Equipment, Radiation Protection, Patient, Orthopedics and Traumatology Clinic

\section{Introduction}

What is the C-arm X-ray system?

It is diagnostic equipment consisting of the following main parts:

- Mobile station consisting of monitors, printer for images and reports, keyboard etc. [5] (Figure 1).

- C-arm stand: image intensifier or flat detector, X-ray tube, CCD senor, X-ray generator, collimating device for the $\mathrm{X}$-rays, control panel, exposure switch and/or exposure pedal etc. [5] (Figure 2).

The $\mathrm{C}$-arm carries the $\mathrm{X}$-ray tube and the image intensifier or the flat detector. This special design enables surgeons to easily direct the X-ray beam to different angles and directions for the particular diagnostic procedure. This rotation of the $\mathrm{C}$-arm facilitates the use of the equipment for various interventions on the patient and thus a considerable reduction of time for the surgical intervention is achieved [6].

This type of X-ray equipment is crucial in orthopedics and traumatology clinics. In the various procedures in orthopedic and traumatological practice, the C-arm is most often used for:

- obtaining an initial real image of the condition of the injured part of the body; 


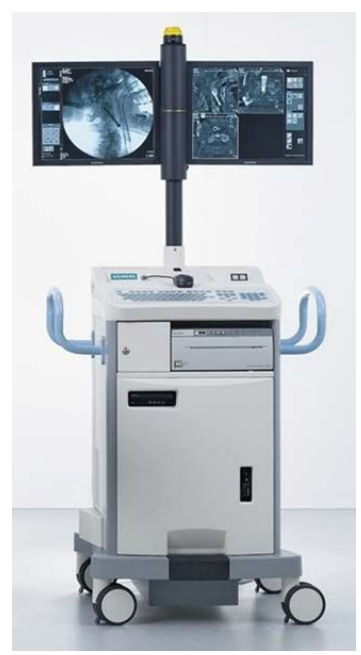

Figure 1. Mobile station [5].

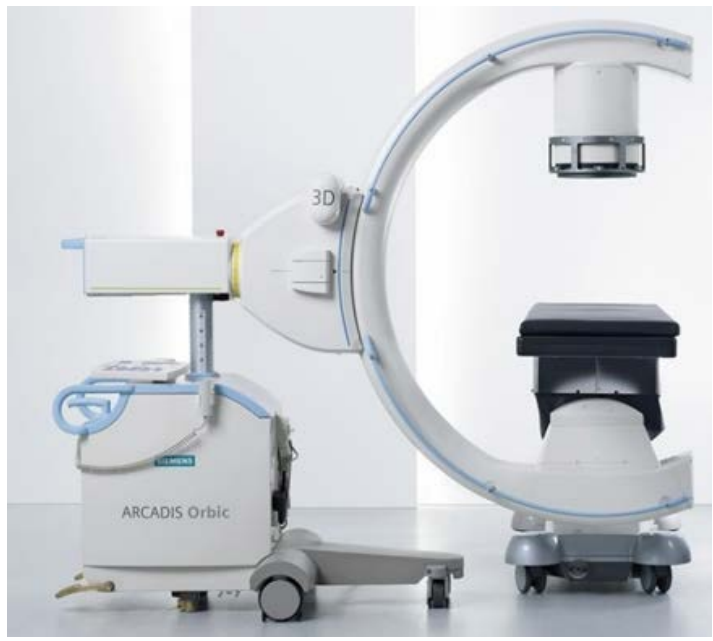

Figure 2. C-arm stand [5].

- obtaining a real image of the condition of the injured part after the performed procedure.

This information is collected from an X-ray image of the region of interest from the patient's body. The image itself is obtained by irradiating the object with X-rays (Figure 5), where the X-ray beam is generated by the X-ray tube (Figure 3). The beam is attenuated when passing through the body and at the end the radiation is detected by an image intensifier or a flat detector where an image is projected (Figure 4).

$\mathrm{X}$-rays are shortwave, high-energy electromagnetic waves, i.e. they are a type of electromagnetic radiation. Their wavelengths range from about $3 \mathrm{~nm}$ to about $10 \mathrm{pm}$ and in the spectrum of electromagnetic waves occupy in the spectrum a place between ultraviolet rays and gamma rays.

The transparency of the different materials for the respective photon energy, i.e. the penetration power of the $\mathrm{X}$-rays changes with the wavelength. $\mathrm{X}$-rays are divided into two groups: 


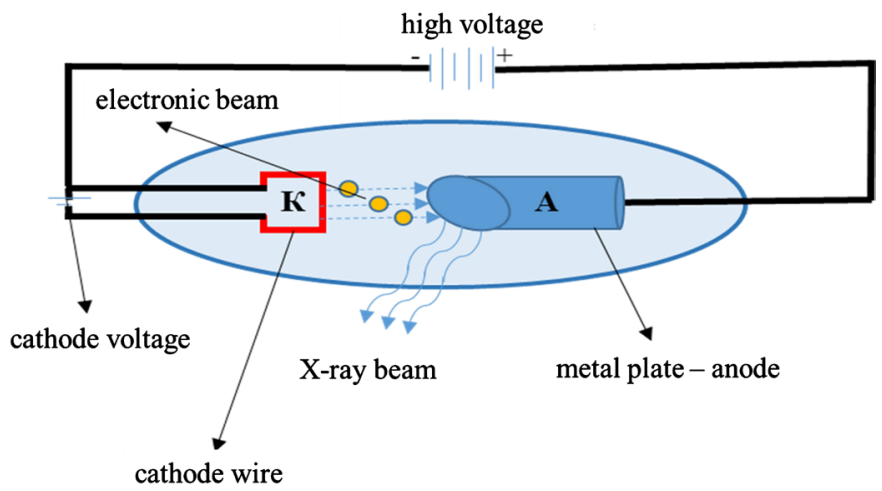

Figure 3. Construction of the X-ray tube.

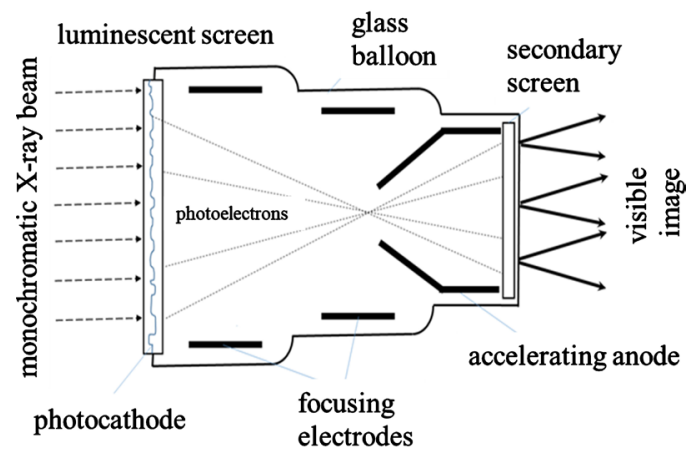

Figure 4. Image intensifier.

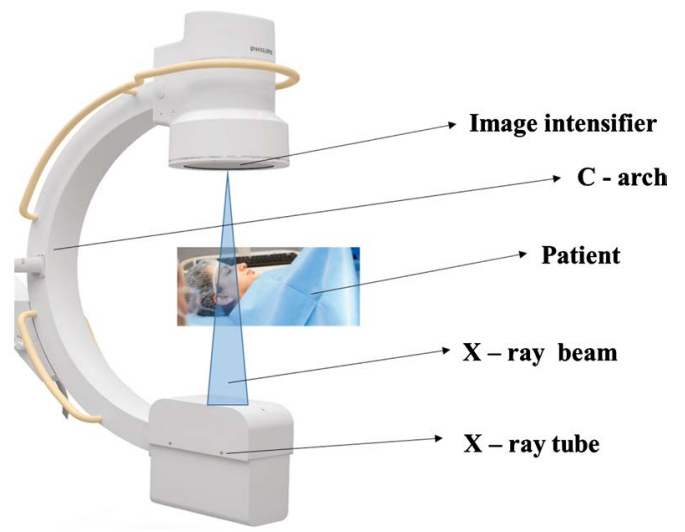

Figure 5. Irradiation of the examined object with X-rays.

- Hard X-rays-photon energy between 12 and $120 \mathrm{keV}$ and wavelength from 0.1 to $0.01 \mathrm{~nm}$. They have high penetrating properties and are poorly absorbed by the substance. For this reason, they are preferred for X-ray imaging;

- Soft X-rays-photon energy between 0.12 and $12 \mathrm{keV}$ and wavelength from 10 to $0.1 \mathrm{~nm}$. They have a weak penetrating property and are strongly absorbed by the substance. For this reason, they are more harmful than hard rays [7].

The properties of X-rays are widely used for diagnostics and treatment. Along with the positive effects, X-rays also can be harmful. For this reason, well-trained 
personnel are required to work with X-ray systems. To reduce the harmful effects of X-rays, strict rules and measures for radiation protection have been developed and introduced, the implementation of which is strictly monitored. In addition to these rules, when a new X-ray equipment is commissioned, it is necessary to apply additional measures for radiation protection arising from the relevant design and parameters of the equipment. When performing $\mathrm{X}$-ray procedures with a $\mathrm{C}$-arm X-ray system, the patient needs radiation protection from scattered X-rays. The region of interest receives direct $\mathrm{X}$-rays, which are needed for the procedure. The rest of the patient's body is exposed to scattered X-rays. This scattered radiation is obtained from the reflection of the radiation from parts of the X-ray equipment, from the patient's table, from the patient's body, the surgeon and his assistant and from the various objects in the room where the procedure is performed. For maximum protection, this part of the patient's body should be covered with a protective material (most often this is a lead-rubber apron).

Considering the possibility of changing the location of the X-ray tube, it is important to place the protecting material properly. In the most conventional $\mathrm{X}$-ray devices, the X-ray tube is positioned above the patient support. In this situation, to protect the part of the patient's body that is exposed to scattered radiation, it is sufficient to place the radiation protection on the body. However, this is not always effective in $\mathrm{C}$-arm procedures due to changing the location of the $\mathrm{X}$-ray tube. It can be positioned not only above and below the patient support, but also at different angles to it. The different types of $\mathrm{C}$-arm movements offer the surgeon a great advantage in directing the $\mathrm{X}$-ray beam in the required direction when examining different parts of the body (Figures 6-10) [5].

In orthopedics and trauma clinics, X-ray examinations of the limbs (arms and legs) or head are often required. The main X-ray beam is directed to the area of

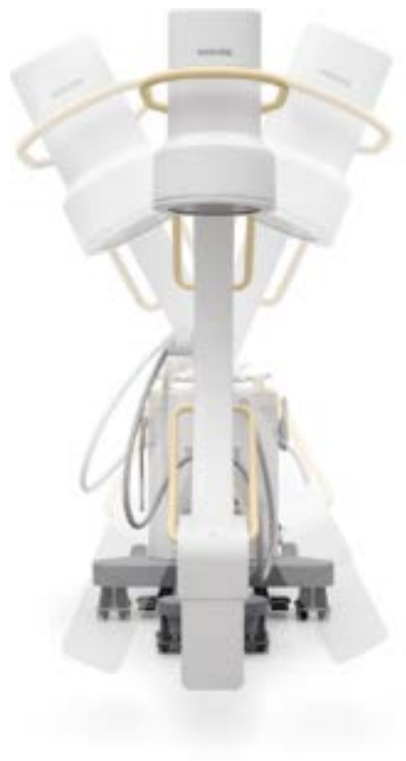

Figure 6. Rotation $-180^{\circ}$ to $+180^{\circ}$ [5]. 


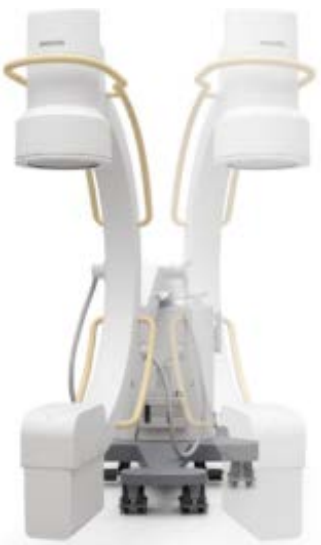

Figure 7. Wig/Wag movement to the left and to the right $-12.5^{\circ}$ to $+12.5^{\circ}[5]$.

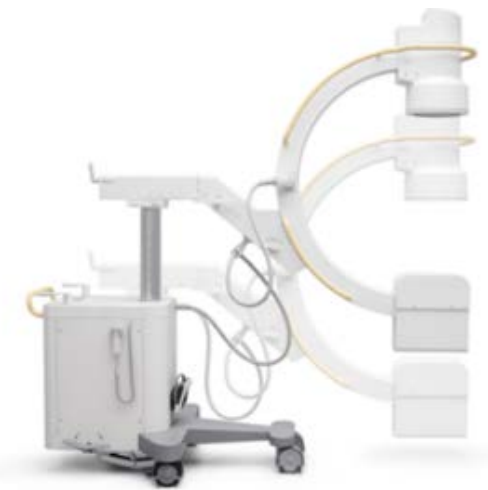

Figure 8. Vertical movement $-3 \mathrm{~cm}$ to $+40 \mathrm{~cm}[5]$.

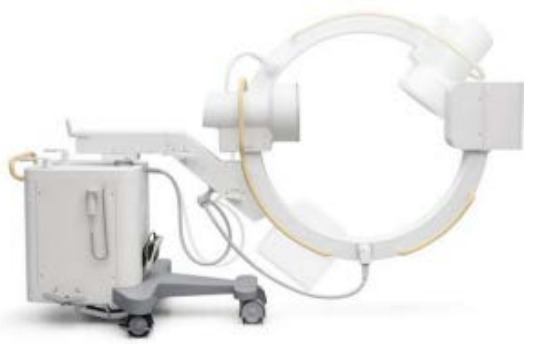

Figure 9. Rotation $-35^{\circ}$ to $+90^{\circ}$ when the C-arm is above $0 \mathrm{~cm}[5]$.

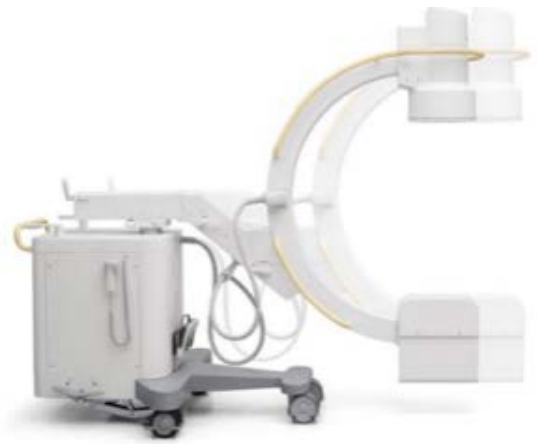

Figure 10. Longitudinal movement $0 \mathrm{~cm}$ to $20 \mathrm{~cm}$ [5]. 
interest. In this case scattered X-rays are also observed (coming from the object, from the patient support, from the body of the person using the equipment and from other parts of the equipment or objects in the room), which is absorbed in the whole body of the patient. This requires that the rest of the patient's body to be protected from the scattered radiation.

Due to the fact that $\mathrm{X}$-rays act mainly on young, rapidly dividing cells, the radiation is most dangerous for children and pregnant women. For this reason, the attention to radiation protection of such patients must be increased. The age group of young people is not to be neglected either. It is a well known fact that the human body grows and develops until about 25 years of age. For this reason, special attention is also paid to this age group when it comes to radiation protection during X-ray examinations. This does not mean that the radiation protection of adult patients should be neglected.

\section{Methods}

\section{Main Method}

The main method we have used in our measurements was dosimetry.

Based on the information above, our research aimed to measure the dose received by the patient's body for different positions of the X-ray tube and for different positions of the radiation protection.

The practical measurements were made in the Clinic of Orthopedics and Traumatology of University Hospital St. Marina Varna, Bulgaria.

\section{Practical Measurements}

\subsection{Participants}

Participants in the dosimetric measurement:

- author of the article,

- service engineer maintaining the X-ray equipment-the measurements were carried out under the direct and continuous control of the service engineer of the X-ray system,

- medical physicist of the hospital who works with the measuring equipment,

- surgeon-a specialist from the clinic of orthopedics and traumatology with instructions about the used medical procedures.

\subsection{Devices and Materials}

For our measurements we used a mobile C-arm X-ray system Philips BV Vectra, which was positioned in the hall of the Clinic of Orthopedics and Traumatology (Figure 11).

The dosimeter used for the measurement was FH 40 G-L Multi-Purpose Digital Survey Meter, which is suitable for our measurements (Figure 12). Figure 12(a) shows the appearance of the device, and Figure 12(b) - its specifications.

For the measurements we used a phantom.

For the phantom we used a plastic bottle with a volume of 11 liters filled with 


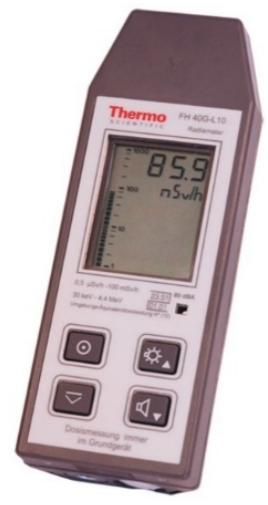

(a)

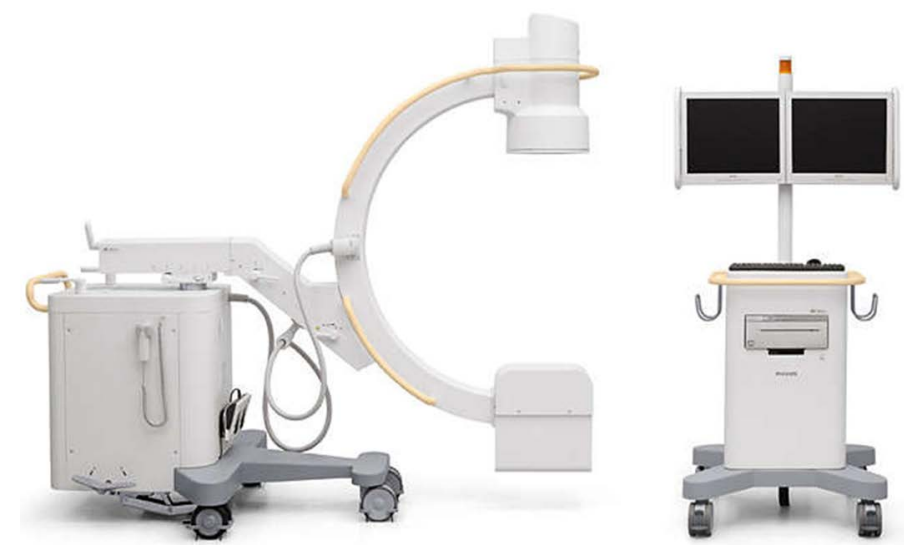

Figure 11. X-ray system BV Vectra-mobile C-arm (Philips India Limited, INSTRUCTIONS FOR USE, BV Vectra, Document version 1.4, Plot No. B-79, MIDC).

\begin{tabular}{|c|c|c|c|c|}
\hline \multicolumn{5}{|c|}{ Specifications } \\
\hline Measured variable & FH $40 \mathrm{G}$ & FH 40 G.L $\Omega$ & FH 40 G-10 & FH 40 GL-10 \\
\hline & \multicolumn{2}{|c|}{ Photon equivalent dose rate $\left[\dot{H}_{x}\right]$} & \multicolumn{2}{|c|}{$\begin{array}{l}\text { Ambient eguivalent dose rate } \\
\qquad H \star(10)]\end{array}$} \\
\hline Measuring Range & $\begin{array}{l}10 \mathrm{nSv} / \mathrm{h}- \\
1 \mathrm{~Sv} / \mathrm{h}\end{array}$ & $10 \mathrm{nSv} / \mathrm{h}-100 \mathrm{mSv} / \mathrm{h}$ & $\begin{array}{l}10 \mathrm{nSv} / \mathrm{h}- \\
1 \mathrm{~Sv} / \mathrm{h}\end{array}$ & $\begin{array}{l}10 \mathrm{nSv} / \mathrm{h}- \\
100 \mathrm{mSv} / \mathrm{h}\end{array}$ \\
\hline Overload capacity & \multicolumn{4}{|c|}{ Transient, $\min$. at $50 \mathrm{~Sv} / \mathrm{h}$} \\
\hline Effect & \multicolumn{4}{|c|}{$\begin{array}{l}\text { Error due to after-effect of transient radiation with max. } \\
50 \mathrm{~Sv} / \mathrm{h} \text { (DIN } 6818 \text { ) is negligible. }\end{array}$} \\
\hline Energy range & \multicolumn{2}{|r|}{$36 \mathrm{keV}-1.3 \mathrm{MeV}$} & \multicolumn{2}{|c|}{$33 \mathrm{keV}-3 \mathrm{MeV}$} \\
\hline $\begin{array}{l}\text { Angular } \\
\text { dependency }\end{array}$ & \multicolumn{4}{|c|}{$\begin{array}{l}\text { Less than } 20 \% \text { at an angle of incidence between }-75^{\circ} \text { and }+75^{\circ} \\
\text { with respect to the unit's longitudinal axis. }\end{array}$} \\
\hline Reading error & \multicolumn{4}{|c|}{ Typical < $5 \%$ max. $20 \%$ : at ${ }^{137} \mathrm{Cs}$ radiation ( $E=662 \mathrm{keV}$ ) } \\
\hline Size & \multicolumn{4}{|c|}{$195 \mathrm{~mm} \times 73 \mathrm{~mm} \times 42 \mathrm{~mm}$} \\
\hline Weight & \multicolumn{4}{|c|}{ Approximately $410 \mathrm{~g}$ (without batteries) } \\
\hline Colour & \multicolumn{4}{|c|}{ gray } \\
\hline Enclosure & \multicolumn{4}{|c|}{ Polycarbonate (Makrolon) } \\
\hline Protection rating & \multicolumn{4}{|c|}{ IP 67 (waterproof up to $1 \mathrm{~m}$ depth) } \\
\hline Batteries & \multicolumn{4}{|c|}{$\begin{array}{l}2 \text { AN LR6 cells 10 IEC86-2 }(1.5 \mathrm{~V}) \\
\text { or } 2 \text { Lithium batteries } 1.5 \mathrm{~V}\end{array}$} \\
\hline Battery service life & \multicolumn{4}{|c|}{$\begin{array}{c}>250 \mathrm{~h} \text { (AA) LR6 cells) }>500 \mathrm{~h} \text { (Lithium cells. FR6) } \\
>4000 \mathrm{~h} \text { in standby mode, with external probes see Table } 19\end{array}$} \\
\hline
\end{tabular}

(b)

Figure 12. FH 40 G-L Multi-Purpose Digital Survey Meter (a) and its specification (b).

water (Figure 13). The phantom was placed on the patient's table, directly under the X-ray beam.

As a protective barrier against X-rays, we used a lead rubber apron with a lead equivalent of $1 \mathrm{~mm}$. We placed it in two layers on the phantom so that the lead equivalent of protection became $2 \mathrm{~mm}$ (Figure 14).

\subsection{Procedure}

During our measurements, we irradiated the phantom using the two main modes of the C-arm-radiography (single shot) and low-dose fluoroscopy (LDF-Light Definition Fluoroscopy). We used the three modes of fluoroscopy-continuous fluoroscopy, 1/2 dose fluoroscopy and pulse fluoroscopy. 


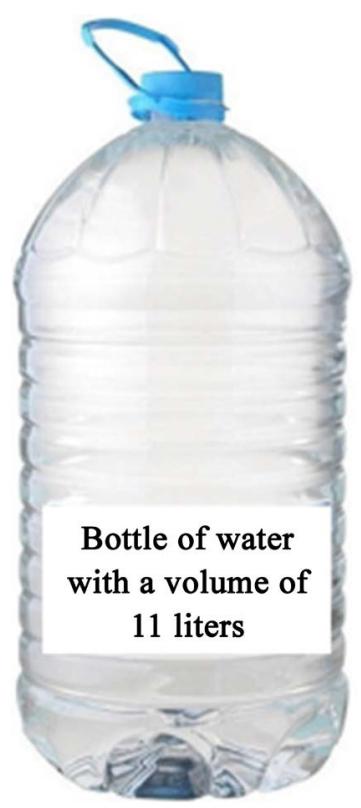

Figure 13. Phantom.

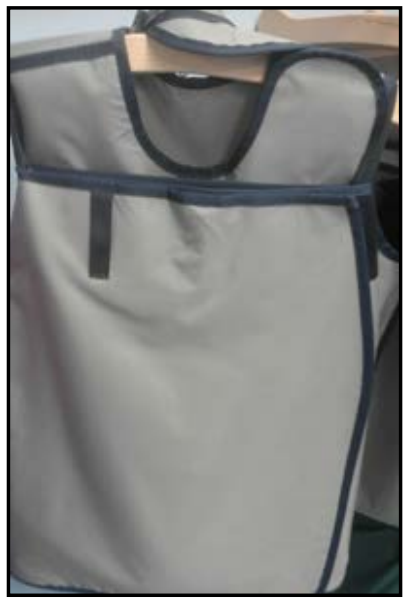

Figure 14. Lead rubber apron.

The operating parameters under which the study was performed are:

radiography (single shot); X-ray tube parameters: $\mathrm{U}=58 \mathrm{kV}$; I.t $=10.35$ $\mathrm{mA} \cdot \mathrm{s}$; duration of the single shot $\mathrm{t}=467 \mathrm{msec}$.

fluoroscopy:

- continuous fluoroscopy; X-ray tube parameters: $\mathrm{U}=58 \mathrm{kV}$; I.t $=3.45 \mathrm{~mA} \cdot \mathrm{s}$; exposure time $\mathrm{t}=3 \mathrm{sec}$.,

- $1 / 2$ dose fluoroscopy; X-ray tube parameters: $\mathrm{U}=58 \mathrm{kV}$; I.t $=3.45 \mathrm{~mA} \cdot \mathrm{s}$; exposure time $\mathrm{t}=6 \mathrm{sec}$.,

- pulse fluoroscopy; X-ray tube parameters: $\mathrm{U}=58 \mathrm{kV}$; I.t $=3.45 \mathrm{~mA} \cdot \mathrm{s}$; exposure time $\mathrm{t}=6 \mathrm{sec}$.

The parameters of the different modes are selected so that the dose of the patient is almost the same. The dose measurement is performed near the middle of the phantom (the bottle with water), at a distance of $15 \mathrm{~cm}$ above it. The distance 
of the X-ray tube to the patient support is $70 \mathrm{~cm}$.

Positions of the X-ray tube, used for the practical measurements are following:

- above and under the patient support (Figure 15 and Figure 16);

- at an angle 0, 30 and 60 degrees to the patient support (Figures 17-19).

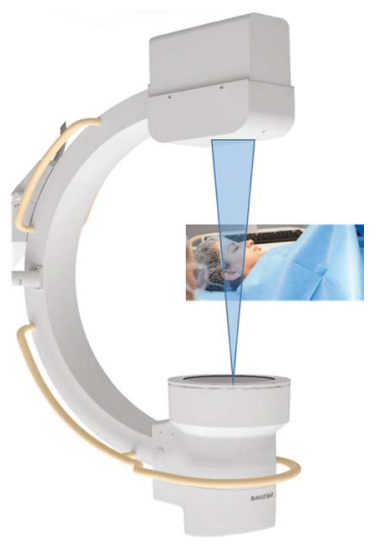

Figure 15. X-ray tube above the patient support.

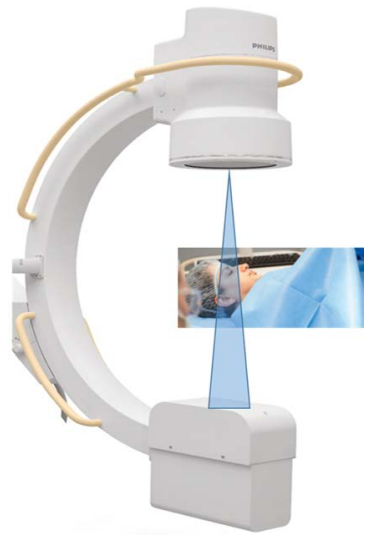

Figure 16. X-ray tube under the patient support.

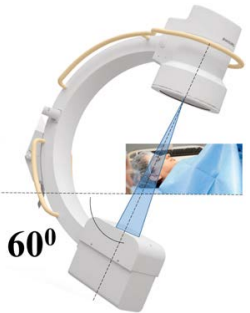

Figure 17. X-ray tube at an angle of $60^{\circ}$ to the patient support.

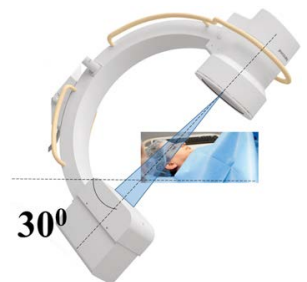

Figure 18. X-ray tube at an angle of $30^{\circ}$ to the patient support. 


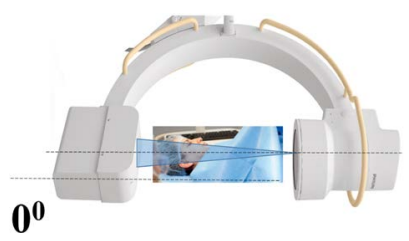

Figure 19. X-ray tube at an angle of $0^{\circ}$ to the patient support.

Description of the measurement.

Each measurement with the specified operating parameters and positions is repeated 5 to 10 times.

During the real procedure, at least two staff members are present in the room-a surgeon-operator and his assistant. No one was present in the hall during our measurements. Our phantom was a bottle of water that is smaller in volume and size than a real patient's body.

Our team was in the hallway, in front of the treatment room, to reduce the radiation we would receive during the measurements. For this reason, we brought out the mobile monitoring station in order to monitor the parameters and images. Only the C-arm stand remained in the hall, and we left the door between the hall and the corridor open. The measuring device was placed on a special stand in the room. This stand has the ability to move horizontally and vertically and thus we could place the device in different positions relative to the patient and the X-ray tube.

Under these conditions of our measurement, the data we received would differ from the data under actual procedures but the difference would not be significant. Moreover, the measured values are quite low. Therefore, we believe that the data obtained can be used to assess the dose load of the patient, which would help to select an appropriate position for protection against scattered radiation for the part of the patient's body that is not in the region of interest for the specific procedure.

\section{Results}

At different positions of the X-ray tube and the protective shield placed on the patient's body, 5 to 10 repetitions of measurements were made for the same parameters of the X-ray tube.

Table 1 shows the average values (from the same type of measurements) for the dose absorbed by the patient's body in $\mu$ Sv, measured at different positions of the $\mathrm{C}$-arm and different positions of the protective shielding. The results are better visible in the diagrams for each position of the $\mathrm{X}$-ray tube (Diagrams 1-5). Here, the dose values are transformed on a scale of $\times 10^{-3}$ to better reveal the difference. The values of all of our patient dose measurements are in the range of $0.12 \mu \mathrm{Sv}$ to $0.23 \mu \mathrm{Sv}$ if we do not take the zero value into account. Of course, the highest values are observed when no shielding is placed, at all positions of the C-arm. The values range from $0.19 \mu \mathrm{Sv}$ to $0.23 \mu \mathrm{Sv}$.

The highest values were measured in the radiography mode (single shot) in 
the range between $0.21 \mu \mathrm{Sv}$ and $0.23 \mu \mathrm{Sv}$. At all positions of the X-ray tube the value was at the maximum, namely $0.23 \mu \mathrm{Sv}$. Only at the position below the patient table the measured value was at the lower limit $-0.21 \mu \mathrm{Sv}$.

For the three fluoroscopy modes, the values were between $0.19 \mu \mathrm{Sv}$ and 0.23 $\mu \mathrm{Sv}$. The minimum value of $0.19 \mu \mathrm{Sv}$ was measured at the position of the X-ray tube below the patient table for two of the fluoroscopy modes- $1 / 2$ dose fluoroscopy and pulse fluoroscopy. The highest values were measured in continuous

Table 1. Average values on the dose absorbed by the patient's body in $\mu \mathrm{Sv}$, measured at different $\mathrm{C}$-arch positions and different barrier positions.

\begin{tabular}{|c|c|c|c|c|c|}
\hline Position of the X-ray tube & $\begin{array}{l}\text { Position of } \\
\text { the protect }\end{array}$ & single shot & continuous & $1 / 2$ dose & pulse \\
\hline \multirow[t]{3}{*}{ above the patient support } & A & 0.023 & 0.021 & 0.020 & 0.020 \\
\hline & B & 0.000 & 0.000 & 0.000 & 0.000 \\
\hline & $\mathrm{C}$ & 0.023 & 0.021 & 0.020 & 0.020 \\
\hline \multirow[t]{3}{*}{ bellow the patient support } & A & 0.021 & 0.020 & 0.019 & 0.019 \\
\hline & B & 0.021 & 0.020 & 0.019 & 0.019 \\
\hline & $\mathrm{C}$ & 0.000 & 0.000 & 0.000 & 0.000 \\
\hline \multirow{4}{*}{$\begin{array}{l}\text { at an angle of } 60^{\circ} \text { to the patient } \\
\text { support }\end{array}$} & A & 0.023 & 0.023 & 0.021 & 0.021 \\
\hline & B & 0.023 & 0.023 & 0.021 & 0.021 \\
\hline & $\mathrm{C}$ & 0.014 & 0.013 & 0.013 & 0.012 \\
\hline & $\mathrm{D}$ & 0.000 & 0.000 & 0.000 & 0.000 \\
\hline \multirow{4}{*}{$\begin{array}{c}\text { at an angle of } 30^{\circ} \text { to the patient } \\
\text { support }\end{array}$} & A & 0.023 & 0.022 & 0.021 & 0.021 \\
\hline & B & 0.023 & 0.022 & 0.021 & 0.021 \\
\hline & $\mathrm{C}$ & 0.020 & 0.019 & 0.018 & 0.018 \\
\hline & $\mathrm{D}$ & 0.000 & 0.000 & 0.000 & 0.000 \\
\hline \multirow{4}{*}{$\begin{array}{l}\text { At an angle of } 0^{\circ} \text { to the patient } \\
\text { support }\end{array}$} & A & 0.023 & 0.023 & 0.021 & 0.020 \\
\hline & B & 0.023 & 0.023 & 0.021 & 0.020 \\
\hline & $\mathrm{C}$ & 0.023 & 0.023 & 0.021 & 0.020 \\
\hline & $\mathrm{D}$ & 0.000 & 0.000 & 0.000 & 0.000 \\
\hline
\end{tabular}

A-without protection; B-on the patient body; C-under the patient body; D—at the side of the X-ray tube, at right angle to the beam.

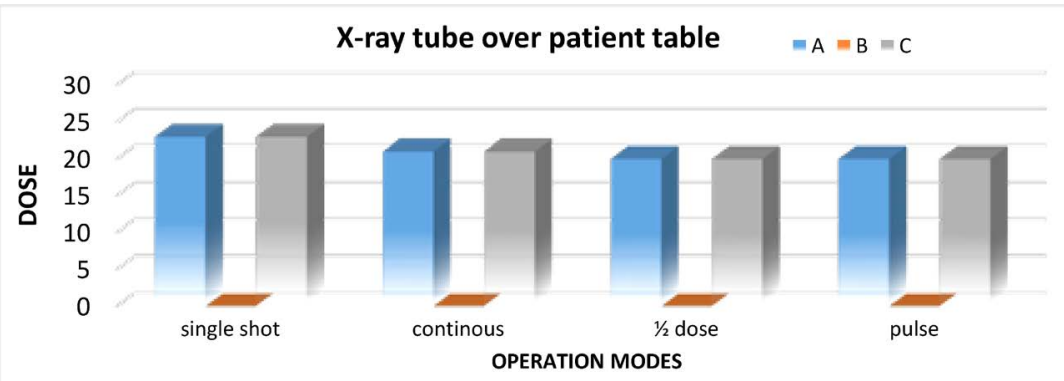

Diagram 1. Dose, received by the patient when the X-ray tube is placed above the patient table. 


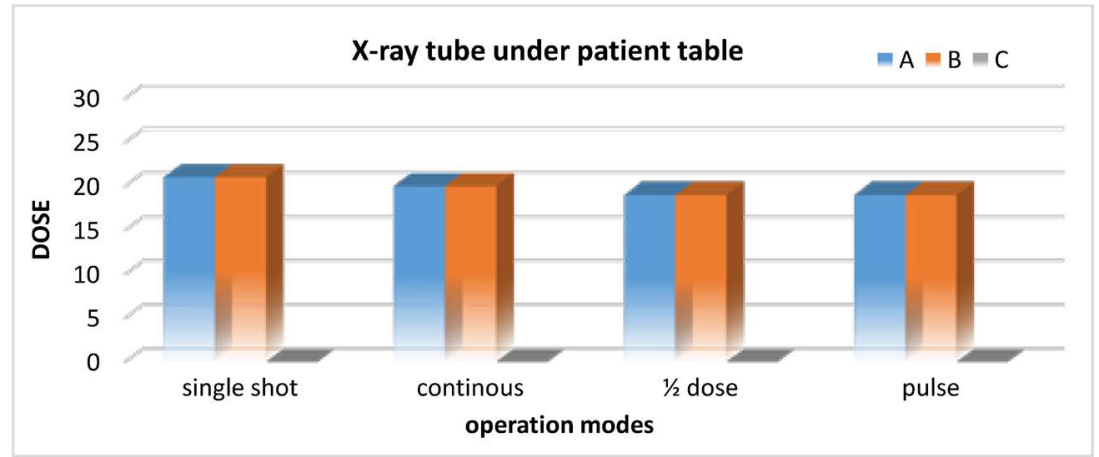

Diagram 2. Dose, received by the patient when the X-ray tube is placed under the patient table.

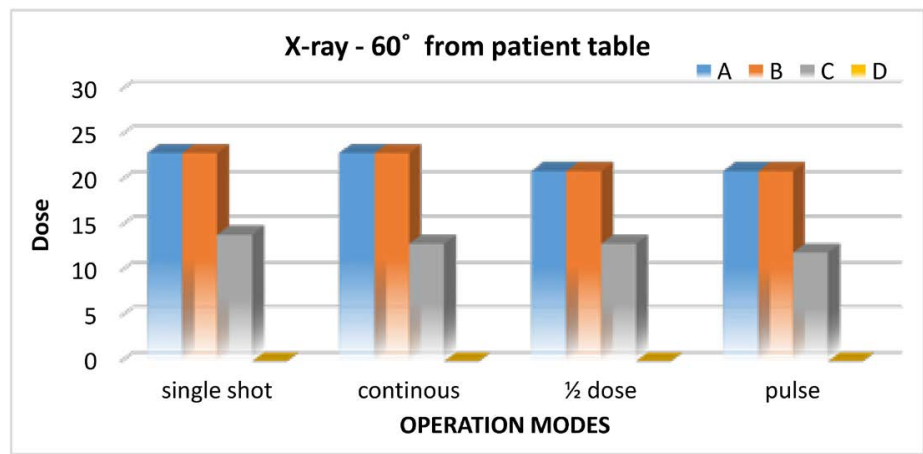

Diagram 3. Dose, received by the patient when the X-ray tube is placed at $60^{\circ}$ to the patient table.

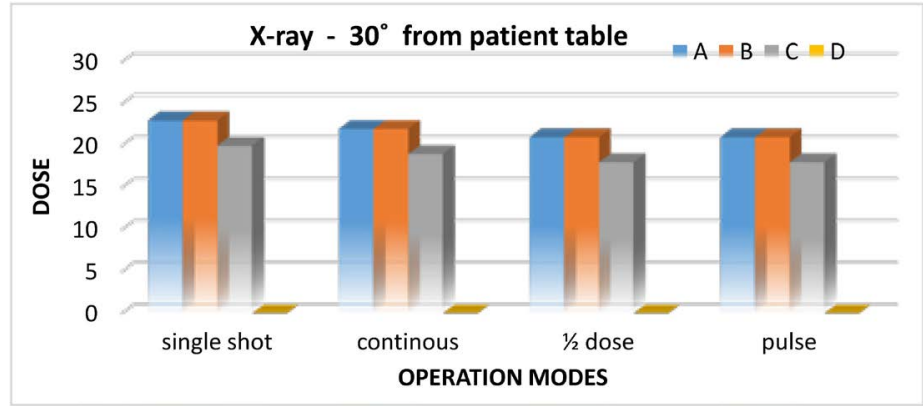

Diagram 4. Dose, received by the patient when the X-ray tube is placed at $30^{\circ}$ to the patient table.

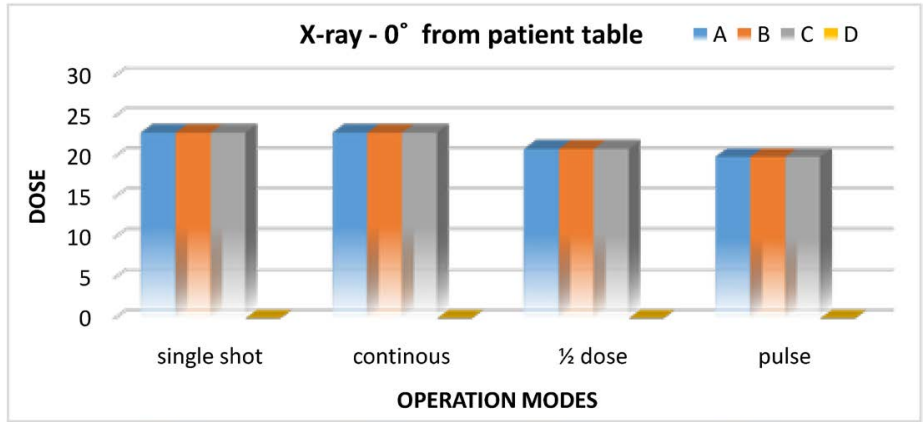

Diagram 5. Dose, received by the patient when the X-ray tube is placed at $0^{\circ}$ to the patient table. 
fluoroscopy mode for two positions of the X-ray tube-rotated at 0 and 60 degree. It should be noted that of the three fluoroscopy modes, the values are highest in continuous fluoroscopy and for the other two modes the values are comparable-they differ by a maximum of 0.02 .

When comparing the values of the patient dose in the position of the protective shielding placed on the patient's body, values in the range from $0.19 \mu \mathrm{Sv}$ to $0.23 \mu \mathrm{Sv}$ are again observed. In this case again, in the radiography mode the values are the highest, in the range from $0.21 \mu \mathrm{Sv}$ to $0.23 \mu \mathrm{Sv}$. The values at this position of the protective shielding for different positions of the X-ray tube, repeat those for the measurements made without protection. Only at the position where the X-ray tube is above the patient table, the value is 0 (Diagram 1 ). Comparing the fluoroscopy modes, for the same position of the protective shielding, again the highest values were observed in continuous fluoroscopy. In the other two modes, the values are comparable, namely in the range from $0.19 \mu \mathrm{Sv}$ to $0.21 \mu \mathrm{Sv}$. In the case of protective shielding placed under the body of the patient the measured values are almost identical with the previous two cases, namely between $0.12 \mu \mathrm{Sv}$ and $0.23 \mu \mathrm{Sv}$. Here again the maximum values were measured in the radiography mode and the minimum values were measured in the fluoroscopy modes. The lower value was measured in pulse fluoroscopy mode, namely $0.12 \mu \mathrm{Sv}$. Here, the zero value of the dose was measured for the position of the X-ray tube under the patient table (Diagram 2). At this position the patient receives no dose from the scattered radiation.

The protective shielding at right angle to the beam on the side of the X-ray tube is only used for the positions where the X-ray tube is rotated to different angles. At all these positions, again, the radiographic mode shows larger values than the fluoroscopy modes. At all positions of the X-ray tube-rotation to 30 and 60 degrees and in all the modes of operation of the $\mathrm{C}$-arm in this position of the shielding, the measured value for the patient is 0 (Diagrams 3-5). This means that in all these cases the patient receives no dose from the scattered radiation.

\section{Discussion}

\subsection{Conclusions}

The data obtained clearly show that the radiation protection of the patient mainly depends on the position where the radiation protective shielding is attached to the patient's body and at the side of the X-ray tube in relation to the patient.

The conclusions from the data obtained in this study are the following:

1) The values of the received dose without protection and with protection placed on the opposite side of the X-ray tube are the same. This shows that in both cases the patient receives the maximum radiation under these conditions of the X-ray examination. This is the case for all operating modes and for all positions of the X-ray tube.

2) When the X-ray tube is positioned perpendicular to the patient's table, i.e. 
below or above it, full protection is observed when the protection is placed at the side of the X-ray tube. A dose value of $0 \mu \mathrm{Sv}$, obtained in all tested operating modes, clearly shows that in these cases the patient does not receive any radiation from the scattered radiation.

3) In cases where the X-ray tube is positioned at an angle to the patient's table, with a protective shielding placed above or below the patient's body, the same patient dose values are observed in measurements without protection and in cases where the X-ray tube is farther from the protection. Thus, in the described cases the patient receives the maximum dose from the scattered radiation during the given procedure.

4) When the $X$-ray tube is rotated at a certain angle and the protective shielding is placed above or below the patient's body, in cases where the X-ray tube is closer to the protective shielding, the patient receives a dose which is less than the maximum dose. In this configuration, the part of the patient's body that is not in the region of interest is not protected from scattered X-rays.

5) In the case of the tube positioned at an angle, absolute protection for the patient with a dose value of $0 \mu \mathrm{Sv}$ is achieved only when the protective shielding is placed perpendicular to the X-ray beam at the side of the X-ray tube between the patient's body and the X-ray tube.

The general conclusion of our study is that in order to obtain maximum protection from scattered radiation when using $\mathrm{C}$-arm mobile $\mathrm{X}$-ray systems, the patient must be protected with a protecting material at the side of the $\mathrm{X}$-ray tube and this material must be placed perpendicular to the beam pointed to the examined region of interest.

\subsection{Recommendations}

Based on the conclusions of the study, we can offer to the attention of medical staff working with mobile C-arm X-ray systems following the main recommendation:

When performing X-ray procedures with a C-arm system, the patient needs radiation protection from scattered X-rays. For maximum protection, part of the patient's body should be covered with a protective material (lead-rubber apron, vest, etc.). This protective material should be placed at the side of the X-ray tube in front of the patient's body. The radiation protection must be positioned perpendicular to the direction of the beam without obscuring the region of interest.

It is important to follow this recommendation in order to reduce the patient's dose as much as possible during a $\mathrm{C}$-arm examination. Only in this way the patient would not receive an additional dose of scattered radiation.

In summary, for all $\mathrm{X}$-ray systems, we can say that the maximum protection of the patient from scattered radiation is possible when the protective shielding is placed in front of the patient at the side of the X-ray tube perpendicular to the beam direction without covering the region of interest for the relevant procedure. 


\section{Acknowledgements}

- We express our great gratitude to the University Hospital St. Marina Varna and the staff of the Clinic of Orthopedics and Traumatology of the hospital for their permission and assistance during our research.

- We also express our gratitude to Philips, which supported us in our research, providing us with the necessary materials and photos used in the article.

\section{Conflicts of Interest}

The author declares no conflicts of interest regarding the publication of this paper.

\section{References}

[1] Park, M.S. and Lee, K.M., Eds. (2012) Comparison of Operator Radiation Exposure between C-Arm and O-Arm Fluoroscopy for Orthopaedic Surgery. Radiation Protection Dosimetry, 148, 431-438.

[2] Balte, S. (2006) Methods for Measuring Fluoroscopic Skin Dose. Pediatric Radiology, 36, 136-140. https://www.ncbi.nlm.nih.gov/pmc/articles/PMC2663643/

[3] Wong, C.H., Kotani, Y., et al. (2017) Comparison of Intraoperative Radiation Exposure for O-Arm Intraoperativect vs. C-Arm Image Intensifier in Minimally Invasive Lumbar Fusion. Clinics in Surgery, 2, 1558.

http://www.clinicsinsurgery.com/full-text/cis-v2-id1558.php

[4] De Silva, T. and Punnoose, J. (2018) Virtual Fluoroscopy for Intraoperative C-Arm Positioning and Radiation Dose Reduction, Journal of Medical Imaging (Bellingham), 5, Article ID: 015005. https://www.ncbi.nlm.nih.gov/pmc/articles/PMC5812884/

[5] Philips India Limited, INSTRUCTIONS FOR USE, BV Vectra, Document version 1.4, Plot No. B-79, MIDC, Phase-II, Chakan Taluka-Khed, Village-Savardari, District: Pune, Maharashtra 410501, India, Issue Number 459800632434.

[6] PHILIPS, History of X-Ray. https://www.philips.com/consumerfiles/newscenter/main/shared/assets/Downloada blefile/FACT_SHEET_X-ray_history.pdf

[7] Илиев, И. and Триндев, П. (2011) Образна диагностика-принципи и апарати, МП И-во на ТУ-София, София. [Iliev, I. and Trindev, P. (2011) Imaging Diagnostics-Principles and Devices. MP Publishing House of TU-Sofia, Sofia.] 